\title{
POSTOPERATIVE RECOVERY; STAPLED HAEMORRHOIDOPEXY VERSUS CONVENTIONAL HAEMORRHOIDECTOMY.
}

\footnotetext{
1. FCPS, MRCS

Assistant Professor

Department of Surgery

Nishtar Medical University/Hospital,

Multan.

2. FCPS

Senior Registrar

Nishtar Medical University/Hospital, Multan.

3. FCPS

Consultant Surgeon

Shahbaz Sharif Hospital, Multan.

4. FCPS

Assistant Professor

Department of Surgery

LUMHS, Jamshoro.

5. FCPS

Assistant Professor

Department of Surgery

Nishtar Medical University/Hospital,

Multan.

6. FCPS, FRCS

Assistant Professor

Department of Surgery

Nishtar Medical University/Hospital,

Multan.
}

\section{Correspondence Address:}

Dr. Ashar Ahmad Khan

Department of Surgery

Nishtar Medical University/ Hospital,

Multan.

asharahmad71@hotmail.com

Article received on:

31/08/2019

Accepted for publication:

$25 / 11 / 2019$

\section{INTRODUCTION}

Haemorrhoids are formed by hypertrophy and congestion of the anal cushions which later on prolapsed with advancement of disease. Exact etiology is unknown but increasing age, dilatation of veins of internal haemorrhoidal plexus and destruction of the supporting tissue are supposed to be the main causes. Other contributing factors are heredity, diet, constipation, occupation and pregnancy. ${ }^{1}$

About $5 \%$ of the general population has some degree of haemorrhoidal disease especially those elder than 40 years. $^{2}$ Haemorrhoids can be external or internal relative to dentate line. ${ }^{3}$
Ashar Ahmad Khan', Tania Mahar², Muhammad Kashif Adnan ${ }^{3}$, Abdul Rasheed Surahio4, Abdul Manan ${ }^{5}$, Irfan Ahmad

RACT... Conventional haemorrhoidectomy, a usual procedure for haemorrhoids in ou many short and long term complications. Some patients complained pain many . were made Stapled haemorrhoidopexy $(\mathrm{SH})$ and conventional haemorrhoidectomy was done in group A and B respectively. SPSS version 20 used for data analysis. Mean and standard deviation were used for quantitative variables including postoperative pain, age and hospital stay. Independent Student t test used for comparison of hospital stay and postoperative pain. Effect modifier including gender, age, duration and grade of haemorrhoids were controlled by stratification and Chi square test was applied. $P$ value less than 0.05 was taken as ignificant. Results: Out of 60 patients, 32 were males and 28 females. In Group A (Stapled ( mean age was $37.37+6.36$ years and $39.17+5.53$ years in Group-B

Key words: $\quad$ Conventional Haemorrhoidectomy, Hospital Stay, Postoperative Pain, Stapled Article Citation: Khan AA, Mahar T, Adnan MK, Surahio AR, Manan A, Ahmad I. haemorrhoidectomy. Professional Med J 2020; 27(1):166-171. DOI: 10.29309/TPMJ/2020.27.1.4098 
cryotherapy, elastic band ligation, infrared and laser photocoagulation. Usually operative treatment is required for grade3 and 4 haemorrhoid. Mostly performed procedure is open haemorrhoidectomy by Milligan - Morgan technique. ${ }^{5}$ In this technique, after surgery patient is left with large, painful perianal wound which take long time to heal. This results in prolong hospital stay and delay in return to work or daily activity. There is another technique in which perianal wound is closed called Ferguson technique of closed haemorrhoidectomy. ${ }^{6}$ This technique is technically more demanding and studies showed same degree of post-operative pain as that was found in open technique. ${ }^{7}$

In 1998, Antonio Longo present alternative way of haemorrhoidectomy ie stapled haemorrhoidectomy. ${ }^{8}$ Rim of mucosa from anal canal is excised just above the dentate line by using circular staple gun. It reduce the blood supply of the haemorrhoid, elevate and reposition the anal cushions. There is no wound on highly sensitive perianal skin. Many studies reported short hospital stay, decrease postoperative pain and early return to work after stapled haemorrhoidectomy. Many changes were made in the name of the procedure and now finally accepted by international committee is staple haemorrhoidopexy. ${ }^{9}$

In our setup, mostly haemorrhoidectomy is performed by open technique. Many of our patients are complaining postoperative pain even after a month of surgery and this results in delay in return to work and daily life activities. This drive us to do a research to compare new staple haemorrhoidopexy technique with our conventional open haemorrhoidectomy.

\section{MATERIAL AND METHODS}

This randomized clinical trial was conducted at Surgery department of Nishtar Medical University and hospital, Multan from 01-01-2018 to 31-12-2018. Using non-probability consecutive sampling, 60 patients more than 12 years of age, having internal haemorrhoid of grade 3 or 4 and admitted through OPD were included in this study. They were having disease for less than 2 year duration. Patients with history of anorectal surgery, concomitant anorectal disorder, fecal incontinence, pregnancy, colorectal malignancy, unfit for surgery and refused to participate were excluded from the study.

Before starting the study approval was taken from the hospital ethical committee. Informed consent was taken from the patients. Patients were divided randomly in to two equal groups of 30, A and B by Draws method. Group A patients allocated for stapled haemorrhoidopexy $(\mathrm{SH})$ and Group B for conventional haemorrhoidectomy $(\mathrm{CH})$. All the operations were done by senior registrars or above. Researchers did the follow up of the patients and entered the data on preformed proforma. Mean postoperative pain was assessed on VAS 24 hours after the surgery and hospital stay was counted from the operative day till discharge.

SPSS version 20 was used for data entry and analysis. Mean and standard deviation were calculated for quantitative variables including postoperative pain, age and hospital stay. Qualitativevariables like gender were presented as percentage and frequency. Independent Student $t$ test was used for comparison of postoperative pain and hospital stay. Effect modifier including gender, age, duration and grade of haemorrhoids were controlled by stratification and Chi square test was applied. $P$ value less than 0.05 was taken as significant.

\section{RESULTS}

Total 60 patients were divided in to two equal groups, Group A underwent stapled hemorrhoidopexy (SH) and Group B underwent conventional haemorrhoidectomy $(\mathrm{CH})$. Mean age in our study was $37.37 \pm 6.36$ and 39.17 \pm 5.53 years in Group A and B respectively. Postoperative pain in Group A was $3.60 \pm 1.27$ and $6.03 \pm 1.73$ in Group B. Postoperative pain was very high in Group B (Stapled haemorrhoidopexy) and $P$ value $=0.000$. Mean hospital stay was 0.90 \pm 0.48 days in Group $A$ and $1.87 \pm 0.57$ days in Group B with $P$ value $=0.000$. There were 32 (53.3\%) males and 28(46.67\%) females in our study. 
Stratification was done on the effects of gender, age and duration of haemorrhoids on surgical outcome. Stapled haemorrhoidopexy was associated with better outcomes regarding postoperative pain and hospital stay in all age groups regardless of their gender, duration and severity of haemorrhoids. Results are shown on Table. No. II and III.

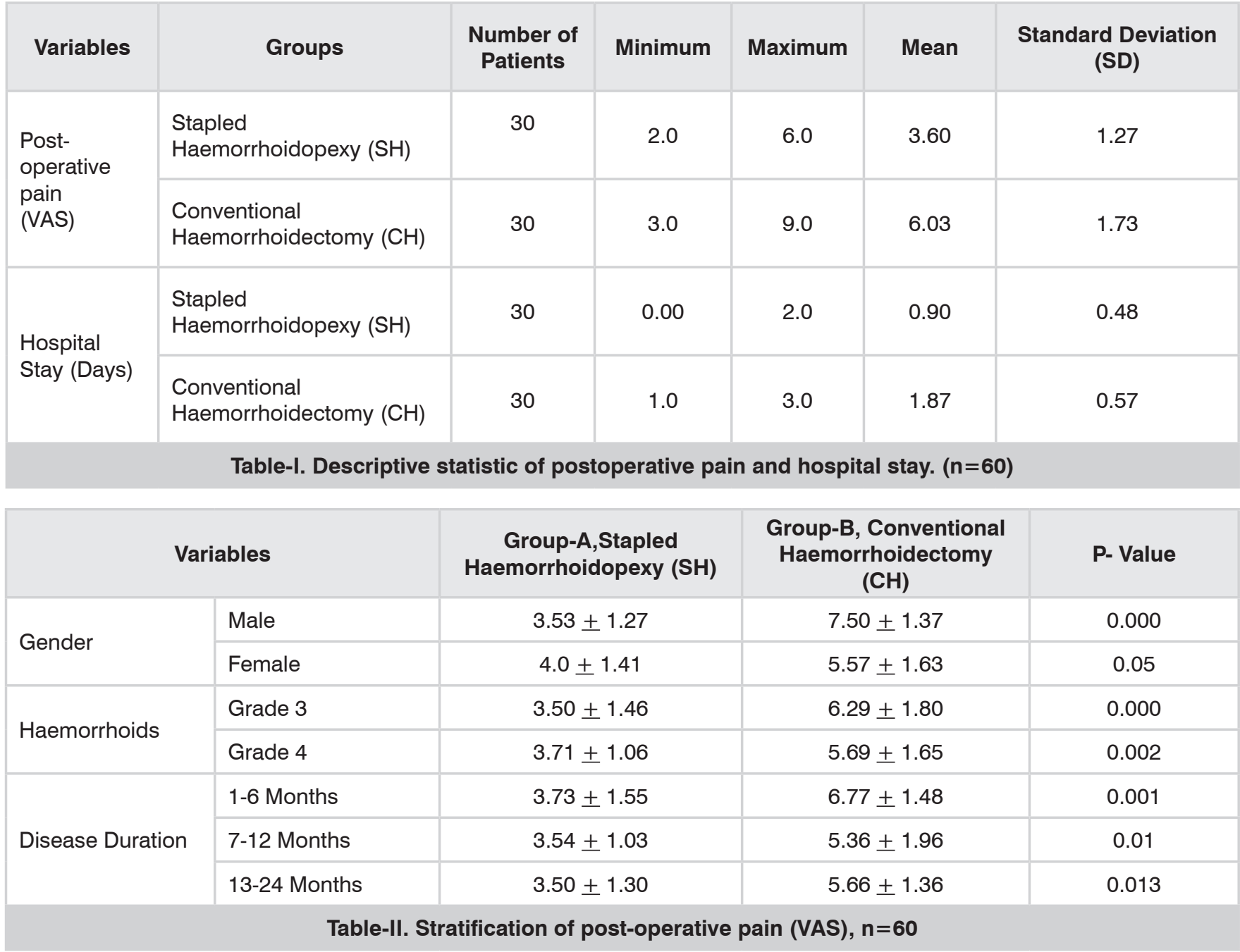

\begin{tabular}{|c|c|c|c|c|}
\hline \multicolumn{2}{|c|}{ Variables } & $\begin{array}{c}\text { Group-A,Stapled } \\
\text { Haemorrhoidopexy (SH) } \\
0.88 \pm 0.43\end{array}$ & $\begin{array}{c}\text { Group-B, Conventional } \\
\text { Haemorrhoidectomy } \\
\text { (CH) } \\
1.83 \pm 0.75\end{array}$ & $\begin{array}{c}\text { P- Value } \\
0.03\end{array}$ \\
\hline & Female & $1.00 \pm 0.82$ & $1.57 \pm 0.53$ & 0.04 \\
\hline Haemorrhoids & Grade 3 & $0.94 \pm 0.44$ & $1.88 \pm 0.44$ & 0.000 \\
\hline \multirow{3}{*}{ Disease Duration } & 1-6 Months & $0.91 \pm 0.53$ & $1.69 \pm 0.48$ & 0.000 \\
\hline & 7-12 Months & $0.90 \pm 0.54$ & $1.90 \pm 0.54$ & 0.00 \\
\hline & 13-24 Months & $0.87 \pm 0.35$ & $2.16 \pm 0.75$ & 0.007 \\
\hline
\end{tabular}




\section{DISCUSSION}

Conventional haemorrhoidectomy has many post-operative complications like bleeding, pain, urinary retention, anal stenosis and incontinence. Many modification have been proposed in the past to improve the post-operative outcome especially to reduce the postoperative pain. In 1998, Longo started an alternative technique, PPH for the surgical treatment of haemorrhoids. ${ }^{8}$ He used the circular staple gun to excise the rim of redundant mucosa of the rectum above the dentate line. The goal is to cut the arterial supply of the haemorrhoid and to lift the redundant anal cushions. In this method, no surgery done on sensitive anal skin which is the cause of pain after conventional haemorrhoidectomy. Many studies done in the past which showed that SH has many benefits like shorter operative time, decrease postoperative pain, decrease chances of urinary retention and early return to work and normal activity. $^{9}$

In our study, two equal groups of 30 patients were made, Group A in which all the patients underwent stapled haemorrhoidopexy (SH) and Group B in which all the patients underwent conventional haemorrhoidectomy $(\mathrm{CH})$. Mean age with SD in our study was $37.37 \pm 6.36$ and $39.17 \pm 5.53$ years in Group A and B respectively. Khan NF from Karachi mentioned mean age of $40.7 \pm 11.6$ years in his study. ${ }^{10}$ Bikhchandani $\mathrm{J}$ mentioned mean age of the patients 46.02 years $(S D=12.33)$ in $\mathrm{SH}$ and 48.64 years $(S D=14.5)$ in open haemorrhoidectomy group. ${ }^{11}$ Shalaby $\mathrm{R}$ showed mean (SD) age of the patients in $\mathrm{SH}$ and open $\mathrm{CH}$ groups 44.1(3.2) and 49.1(12.2) years respectively. ${ }^{12}$ Result from another study from Saudi Arabia showed mean age of 39.6 years. ${ }^{14}$

In this study there were $32(53.3 \%)$ males and $28(46.7 \%)$ females with $M: F$ ratio 1.14:1. Rafaqat Bota from Civil Hospital, Karachi mentioned 83(69.1\%) males and $37(30.9 \%)$ females in his study. ${ }^{13}$ Salman Yousuf Guraya et al mentioned total 30 patients, $21(70 \%)$ males and $9(30 \%)$ females in his study. ${ }^{14}$ In our study patients presented with haemorrhoids of grade 3 were $72.8 \%$ and grade 4 were $27.2 \%$. Rafaqat Bota reported $76.6 \%$ patients with grade 3 and $23.4 \%$ with grade 4 haemorrhoid. Salman Yousuf Guraya reported this as $86 \%$ and $14 \%$.

In this study, mean operating time was 22 minutes in $\mathrm{SH}$ group and 45 minutes in $\mathrm{CH}$ group. Rafaqat Bota et al and Salman Yousuf Guraya et al reported operating time 15-50 minutes (Median=32) and 21.7 minutes (Range 17-36) respectively after stapled haemorrhoidopexy. This study showed mean hospital stay of 0.90 days in Group A with standard deviation of 0.48 and in Group B was 1.87 days with standard deviation of $0.57(p=0.000)$. Khan NF et al mentioned mean hospital stay in SH group $2.03 \pm 0.81$ and in open haemorrhoidectomy group $3.37 \pm 2.2$ days with significant $p$ value $=0.003 .{ }^{10}$ Rafaqat Bota et al and Salman Yousuf Guraya et al mentioned hospital stay of $1-3$ days (Median $=34 \mathrm{H}$ ) and 1.9 days respectively after stapled hemorrhoidopexy.

In our study, mean pain score in Group A was $3.60 \pm 1.27$ while in Group-B was $6.03 \pm$ 1.73 with $\mathrm{P}=0.000$. In $\mathrm{SH}$ group, 11 patients and in $\mathrm{CH}$ group 08 patients have excellent outcome. Our results showed clear dominance of $\mathrm{SH}$ over $\mathrm{CH}$ in regards of postoperative pain. Similar results were shown by many studies. Khan NF report postoperative pain score 4.43 \pm 1.25 in $\mathrm{SH}$ group and $7.37 \pm 0.72$ in open haemorrhoidectomy group. ${ }^{10}$ Rafaqat Bota et al reported very less postoperative pain and need of analgesia after stapled haemorrhoidopexy and 78 out of 120 patients (65\%) were able to be discharged on $1^{\text {st }}$ postoperative day and remaining 42 out of $120(35 \%)$ were discharged on $2^{\text {nd }}$ postoperative day. ${ }^{13}$ Salman Yousuf Guraya et al mentioned the same trend that mild anal pain after defecation was reported by $7 \%$ of the patients. ${ }^{14} \mathrm{E}$. Aytac compared the results of Ferguson haemorrhoidectomy and $\mathrm{SH}$ and report no difference in long term anorectal pain $(p=0.6)$ in both groups in his longest follow up study. ${ }^{15}$ Angus $\mathrm{J} \mathrm{M}$ et al mentioned the comparable results of postoperative pain $2 \%$ in $\mathrm{SH}$ and $3 \%$ in traditional haemorrhoidectomy. ${ }^{16}$

Rafaqat Bota reported some complications other than the postoperative pain were recurrence in $4.16 \%$, anal stenosis in $0.83 \%$ and bleeding in 
$0.83 \%$ of the patients. Three out of 120 patients required readmission for the treatment of their complications. ${ }^{13}$ Salman Yousuf Guraya mentioned 3\% postoperative bleeding and 3\% prolapse after stapled haemorrhoidopexy. ${ }^{14} \mathrm{Col}$. S.S. Jaiswal reported some rare complications like rectal perforation and postoperative thrombosis of external haemorrhoid in $2.5 \%$ patients. ${ }^{9}$ Angus $\mathrm{J} \mathrm{M}$ et $\mathrm{al}^{16}$ mentioned in his study that $\mathrm{SH}$ was less painful postoperatively in short term only and increased recurrence rate after $\mathrm{SH}$ as compared to traditional haemorrhoidectomy. After 12 months, recurrence rate was $32 \%$ in $\mathrm{SH}$ group and $14 \%$ in traditional excision group. After 24 months, it was $25 \%$ and $42 \%$ respectively. Further surgical intervention was required in $9 \%$ patients of $\mathrm{SH}$ group and $6 \%$ patients of traditional excision group. According to Argus $\mathrm{J} \mathrm{M}$ et al $\mathrm{SH}$ was associated with increased cost, recurrence, tenesmus and worst continence. Overall quality of life was better in traditional haemorrhoidopexy. ${ }^{16}$ A Sturiale et al also mentioned high rate of complications after $\mathrm{SH}$, recurrence in $9.3 \%$, incontinence in $39 \%$ and tenesmus in $38.2 \%$ patients. ${ }^{17}$ We found short hospital stay and decrease postoperative pain in $\mathrm{SH}$ group as compared to $\mathrm{CH}$ group. We tried to check the effects of gender, age and grade of haemorrhoid on surgical outcome in both groups and we found no difference in trends. Simillis C mentioned in his meta-analysis study that $\mathrm{SH}$ was associated with faster recovery and decrease postoperative pain but high recurrence rate. ${ }^{18}$

\section{LIMITATIONS}

Sample size is small and there is short follow up. There is need of further clinical trial with large sample size and long follow up.

\section{CONCLUSION}

Stapled haemorrhoidopexy is associated with shorter hospital stay and decrease postoperative pain irrespective of age, sex and grade of the haemorrhoids.

Copyright@ 25 Nov, 2019.

\section{REFERENCE}

1. Corman Ml. Haemorrhoids. In: Corman MI, ed. Colon and Rectal Surgery, 4 $^{\text {th }}$ Ed. Philadelphia: LippincottRaven; 1998: 147-205.
2. Arslani N, Patrlj L, Rajkovik Z, Papes D, Altarac S, A Randomized clinical trial comparing Ligasure versus Stapled Haemorrhoidectomy Surg Laprosc Endosc Percutan Tech 2012; 22:58-61.

3. Afzal M, Dar MF, Arafat MY, Infrared coagulation versus rubber band ligation in the treatment of internal haemorrhoids. A randomized prospective study. Pak Armed Force Med J, 2009; 3:56-9.

4. Schrock TR. Hemorrhoids; Non operative and interventional management. In; Barkin J, O'Phelan CA, editors. Advanced therapeutic endoscopy. New York: Raven Press, 1991.

5. Milligan E, Morgan C (1937). Surgical anatomy of the anal canal and operative treatment of hemorrhoids. Lancet 2: 1119-1124.

6. Ferguson JA, Heaton JR (1959). Closed haemorrhoidectomy. Dis Colon Rectum 2(2): 176-179.

7. Arbman G, Krook H, Haapaniemi S. Closed vs. Open haemorrhoidectomy, Is there any difference? Dis Colon Rectum. 2000, 43:311-334.

8. Longo A. Treatment of hemorrhoids disease by reduction of mucosa and hemorrhoidal prolapse with a circular suturing device: a new procedure. Proceedings of the Sixth World Congress of Endoscopic Surgery. Rome, Itlay; 1998: 777.

9. Col S. S. Jaiswal, Maj Darpan Gupta, Sqn Ldr Saket Davera. Stapled hemorrhoidopexy- Initial experience from a general surgery center. Medical Journal Armed Forces India. 69; (2013): 119-123.

10. Khan NF, Hussain Shah SSH, Bokhari I, Mahboob S, Gulfam MA, Ghayasuddin M, Khan A, Rasul S. Outcome of Stapled haemorrhoidectomy versus Milligan Morgan's. JCPSP. 2009; 19(9):561- DOI: 09.2009/ JCPSP. 561565.

11. Bikhchandani J, Agarwal PN, Kant R, Malik VK. Randomized controlled trial to compare the early and mid-term results of stapled versus open haemorrhoidectomy. The American Journal of Surgery. January 2005; 189(1):56-60.

12. Shalaby R, Desoky A. Randomized clinical trial of stapled versus Milligan-Morgan haemorrhoidectomy. Br J Surg. 2001; 88: 1049-1053.

13. Rafaqat Bota, Mushtaq Ahmed, Adnan Aziz. Is stapled haemorrhoidectomy a safe procedure for third and fourth grade hemorrhoid? An experience at Civil hospital, Karachi. Indian J Surg. December 2015; 77(3): 1057-1060. DOI. 10.1007/s12262-014-1140-4. 
14. Salman Yousuf Guraya, Gamal A Khairy. Stapled Hemorrhoidectomy; Results of a prospective clinical trial in Saudi Arabia. Journal of Clinical and Diagnostic Research. Sep 2013; Vol 7(9): 1949-1952.

15. E. Aytac, E. Gorgun, H.H. Erem, M.A.Abbas, T.L. Hull, F. H. Remzi. Long term outcomes after circular stapled hemorrhoidopexy versus Ferguson haemorrhoidectomy. Tech Coloproctol; (2015) 19: 653-658. DOI: org/10.1007/s10151-015-1366-6.

16. Angus J M Watson, Jemma Hudson, Jessica Wood, Mary Kilonzo, Steven R Brown, Alison McDonald et al. Comparison of stapled hemorrhoidopexy with traditional excisional surgery for hemorrhoidal disease (eTHoS): A pragmatic, multicenter, randomized controlled trial. www.thelancet.com 2016; 388:2375-85. DOI: org/10.1016/50140-6736 (16)318037.
17. Sturiale, B. Fabiani, C. Menconi, D. Cafaro, F. Fusco, G. Bellio, M.Schiano di Viscoute, G. Naldini. Long term results after stapled hemorrhoidopexy: A survey study with mean follow up of 12 years. Volume 22 (9); 689-696. DOI: org/10.1007/s10151-018-1860-8.

18. Simillis C, Thoukididon SN, Slesser AA, Rasheed S, Tan E, Tekkis PP. Systemic review and network meta analysis comparing clinical outcomes and effectiveness of surgical treatment for hemorrhoids. Br J Surg. 2015 Dec; 102 (13): 1603-18. DOI: 10.1002/ bjs.9913.

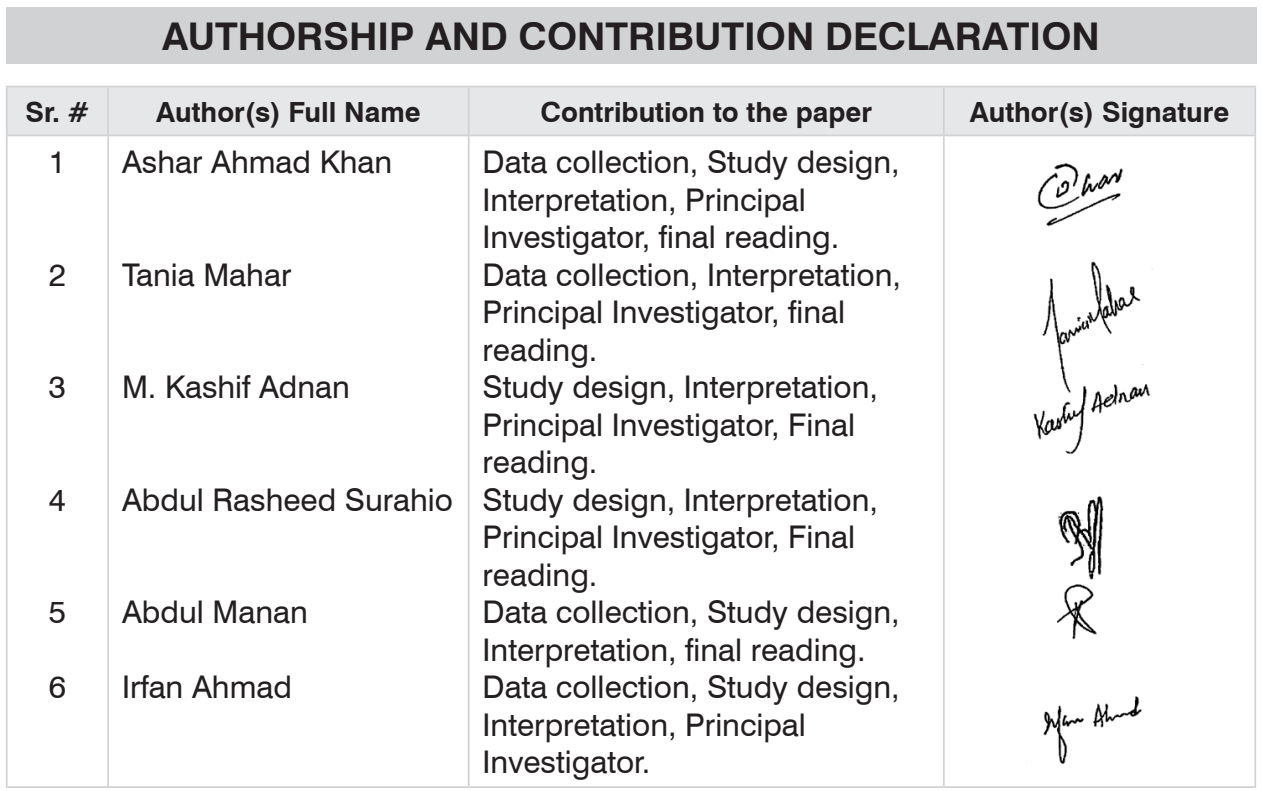

